\title{
ALGUNAS MODIFICACIONES DEL RÉGIMEN DEL SEGURO DE RESPONSABILIDAD CIVIL EN UNA NUEVA LEY ESPAÑOLA DE CONTRATO DE SEGURO"
}

\author{
SOME MODIFICATIONS OF THE CIVIL \\ LIABILITY INSURANCE REGIME IN A NEW SPANISH \\ INSURANCE CONTRACT LAW
}

\author{
MARÍA JESÚS PEÑAS MOYANO** \\ Fecha de recepción: 29 de abril de 2021 \\ Fecha de aceptación:30 de mayo de 2021 \\ Disponible en línea: 30 de junio de 2021
}

Para Citar este artículo/To cite this article

Peñas Moyano, María Jesús. Algunas modificaciones del régimen del seguro de responsabilidad civil en una nueva ley española de contrato de seguro, 54 Rev.IberoLatinoam.Seguros, 163-186 (2021).

https://doi.org/10.11144/Javeriana.ris54.amrs

doi:10.11144/Javeriana.ris54.amrs

\footnotetext{
* Ponencia presentada en el II Congreso Internacional de Derecho del seguro. "Dimensiones y desafíos del seguro de responsabilidad civil”, dirigido por los profesores Abel Veiga Copo y Miguel Martínez Muñoz. Universidad Pontificia de Comillas. ICADE. Madrid, 7, 8 y 9 de octubre 2020

** Doctora en Derecho por la Universidad de Valladolid (1996), Catedrática de Derecho Mercantil en esta Universidad. Ha impartido conferencias y Cursos de Postgrado en varias Universidades españolas, europeas (Lille, Lisboa, Coimbra, Roma, Lecce, Bari, Trento, Pavía, Cerdeña...) e iberoamericanas (Bolivia, Nicaragua, Paraguay) y participado en Congresos relativos a la Unión Europea, Mercosur, Derecho concursal, Sociedades, Banca y Seguros y contratación mercantil. Ha intervenido en varios Proyectos de Investigación financiados por la Junta de Castilla y León y el Ministerio de Economía y Competitividad. ORCID: https://orcid.org/0000-0001-6768-5241. Contacto: chus@eco.uva.es
} 


\title{
RESUMEN
}

La Ley española de contrato de seguro acaba de celebrar su cuarenta aniversario. El tiempo transcurrido desde su entrada en vigor motiva el debate de la elaboración de un nuevo texto que incluya modificaciones también en el régimen del seguro de responsabilidad civil. Algunas de las reformas que deben abordarse en este ámbito se refieren a una correcta delimitación temporal del riesgo, a través de las cláusulas correspondientes para evitar confusiones con una posible limitación de derechos de los asegurados. Ha de reconsiderarse igualmente ejercicio de la acción directa por parte de los terceros perjudicados y el ámbito de las posibles excepciones que se pueden oponer, así como la oportunidad de contemplar en el régimen contractual los seguros de naturaleza obligatoria.

Palabras Clave: contrato de seguro, seguro de responsabilidad civil, delimitación temporal del riesgo, acción directa del tercer perjudicado

\begin{abstract}
Spanish insurance contract law has just celebrated its 40th anniversary. The time elapsed since its entry into force motivates the debate on the development of a new text that also includes modifications in the civil liability insurance regime. Some of the reforms that must be addressed in this area refer to a correct temporal delimitation of risk, through the corresponding clauses to avoid confusion with a posible delimitation of the insured's rights. The exercise of direct action by the injured third parties and the scope of the possible exceptions that may be opposed, as well as the opportunity to consider compulsory insurance in the contractual regime, must also be reconsidered.
\end{abstract}

Keywords: insurance contract, civil liability insurance, delimitation temporal of risk, injured third party direct action

\section{SUMARIO}

I. Introducción: hacia una nueva ley de contrato de seguro. II. Modificaciones en el régimen del seguro de responsabilidad civil. III. Cláusulas de delimitación temporal del riesgo. 1. Reconsideración como cláusulas limitativas. 2. Ampliación de los tiempos de cobertura. 3. Validez de las cláusulas de delimitación temporal del riesgo unidimensionales. IV. La acción directa del tercer perjudicado. 1. Reconsideración del carácter inmune de la acción directa. 2. Relaciones entre la entidad aseguradora, el asegurado y el tercer perjudicado. V. Previsión de los seguros obligatorios de responsabilidad civil. 1. Disposición adicional segunda de la Ley 20/2105, de 14 de julio. 2. Reconsideración de su presencia en la ley reguladora del contrato de seguro. Bibliografía utilizada. 


\section{INTRODUCCIÓN: HACIA UNA NUEVA LEY DE CONTRATO DE SEGURO}

La Ley 50/1980, de 8 de octubre ha celebrado ya sus 40 años si bien, como se sabe, tuvo una vacatio legis bastante generosa al ser publicada en el BOE el 17 de octubre y entrar en vigor el 17 de abril de 1981, permitiendo que su incorporación al sector asegurador tuviera lugar de un modo pausado.

De esta norma, que se erige en la decana de las leyes mercantiles españolas si se deja a un lado el Código de Comercio de 1885, se pueden destacar muchos aspectos positivos. En su momento tuvo una gran importancia en la evolución histórica del Derecho mercantil por su carácter técnicamente avanzado, incluso también desde un punto de vista económico ha tenido una enorme relevancia. Ha contribuido, igualmente, a la modernización del contrato y del sector asegurador en general. Y a día de hoy, a pesar del tiempo transcurrido y las correspondientes modificaciones, continúa siendo una Ley perfectamente aplicable, con una enorme capacidad para resolver problemas prácticos e interpretativos, ya que se trata de una Ley de principios, breve, concisa, entendible y practicable, aunque su carácter imperativo puede hacerla parecer severa incluso, y, sobre todo, se trata de una norma asimilable en cuanto a su estructura y posibilidad de conocimiento por la gran técnica normativa que la caracteriza, algo que sería profundamente deseable para muchas normas elaboradas con posterioridad y, por supuesto, para la normas que se elaboran en el momento actual.

Todas estas lisonjas, sin embargo, no pueden ni deben evitar que se continúe valorando la posibilidad de elaborar un nuevo texto que debe actualizar y mejorar este que seguimos manejando, e incorporar además soluciones jurídicas para los nuevos y numerosos fenómenos que están apareciendo en la práctica (ecosistemas digitales, internet de las cosas, incluido el coche autónomo, big data, análisis genéticos en los seguros de personas, blockchain, contratos inteligentes, inteligencia artificial, riesgos cibernéticos... entre otros $)^{1}$. Si lo que se pretende es elaborar un nuevo texto con algunos retoques estéticos, sin entrar a en el fondo de estas cuestiones fundamentales para dotarlas de un régimen jurídico que aporte seguridad en el mercado asegurador que ya está trabajando con todas estas cuestiones, sería preferible mantener el texto actual.

A lo largo de su vigencia, la Ley 50/1980 ya ha sido objeto de modificaciones parciales diversas $^{2}$ provocadas en ocasiones por la necesaria transposición y adecuación

\footnotetext{
1 AA.VV., Insurtech y nuevas tendencias de la responsabilidad civil, J. Jimeno Muñoz (coord.), Sepin, Madrid, 2109

2 La LCS ha sido reformada por el art. 3 de la Ley 21/1990, de 19 de diciembre, de adaptación del Derecho español a la Directiva 88/357/CEE, sobre libertad de servicios en distintos seguros al de vida y de actualización de la legislación a los seguros privados;

También por la disposición adicional sexta de la Ley 30/1995, de 8 de noviembre de ordenación y supervisión de los seguros privados;

Por la Ley 18/1997, de 13 de mayo, de modificación del artículo 8 de la Ley de Contrato de Seguro para garantizar la plena utilización de todas las lenguas oficiales en la redacción de los contratos;

Por el art. 12 de la Ley 44/2002, de 22 de noviembre, de medidas de reforma del sistema financiero;
} 
a la normativa comunitaria que ha afectado a esta materia y que ha permitido ir actualizándola en aspectos cruciales.

Además de estas modificaciones, se han abordado proyectos de reforma integral, sobre todo, a partir del 25 aniversario de la Ley (en 2007 se elaboró un importante informe sobre las bases para la reforma de la LCS). Entre tales iniciativas ha de destacarse el Anteproyecto de Ley de Contrato de Seguro de 2011, cuya última versión es de 30 de junio, y sobre todo la incorporación del régimen del contrato de seguro al Título VIII "De los contratos de seguros y de mediación de seguros" (arts. 581-1 y ss.) del Libro $\mathrm{V}$, "De los contratos mercantiles en particular", del Anteproyecto de Ley de Código Mercantil, de 30 de mayo de 2014.

El primero de los textos, además de por el cambio de gobierno que tuvo lugar, no prosperó porque resultaba insuficiente a juicio de la mayor parte de la doctrina. ${ }^{3}$ Por su parte, el proyecto de Código Mercantil no ha recibido menos críticas en su conjunto y ante la imposibilidad de su aprobación, al menos, tal y como está concebido en la actualidad, es probable que con el paso de los años se convierta en un documento de referencia ${ }^{4}$. Ha de tenerse en cuenta también que, a nivel europeo, el tratamiento del contrato de seguro dio lugar a los Principios de Derecho europeo del contrato de

\footnotetext{
Por la disposición final vigésima octava de la Ley 22/2003, de 9 de julio, Concursal;
}

Por la Ley 34/2003, de 4 de noviembre, de modificación y adaptación a la normativa comunitaria de la legislación de seguros privados;

Por la disposición adicional décima de la Ley 26/2006, de 17 de julio, de mediación de seguros y reaseguros privados

Por la disposición derogatoria de la Ley 22/2007, de 11 de julio, sobre comercialización a distancia de servicios financieros;

Por la disposición final novena de la Ley 15/2015, de 2 de julio, de la Jurisdicción voluntaria;

Por la disposición final primera de la Ley 20/2015, de 14 de julio, de ordenación, supervisión y solvencia de las entidades aseguradora y reaseguradoras

Se ha introducido una disposición adicional cuarta por el art. 14 de la Ley 26/2011, de 1 de agosto, de adaptación normativa a la Convención internacional sobre derechos de las personas con discapacidad; una disposición adicional quinta sobre no discriminación por razón de VIH/SIDA u otras condiciones de salud por la disposición adicional primera de la Ley 4/2018, de 11 de junio, por la que se modifica el texto refundido de la Ley general para la defensa de los consumidores y usuarios y otras leyes complementarias, aprobado por Real Decreto Legislativo 1/2007, de 16 de noviembre;

También hay que tener en cuenta que su art. 76 e) ha sido declarado inconstitucional y nulo por Sentencia del Tribunal Constitucional (pleno) de 11 de enero de 2018.

3 SAnz PArrilla, M. Sección 6a "Seguro de responsabilidad civil. Introducción y artículos 68 a 7", Revista Española de Seguros, núms. 143-144, 2010, pp. 815 y ss.; BATAller Grau, J. "La reforma de la Ley de Contrato de Seguro", Revista de Derecho Mercantil, núm. 279, 2011, pp. 203 y ss. Con anterioridad, en junio de 2010, la Dirección General de Seguros presentó a la Junta consultiva un Anteproyecto de Ley, que fue el germen de la versión de 30 de junio de 2011.

4 Vid., Tapia Hermida, A.J., "El proceso de reforma del régimen del seguro de responsabilidad civil: desde la vigente Ley de Contrato de Seguro hasta el Anteproyecto de Ley de Código Mercantil. La delimitación objetiva de la cobertura ante la nueva regulación de las condiciones generales y las cláusulas limitativas", Revista española de seguros, núm.158, 2014, pp. 143 y ss. Igualmente, "El seguro de responsabilidad civil en la Propuesta de Código Mercantil”, Revista de la Asociación Española de Abogados Especializados en Responsabilidad Civil y Seguro, núm. 49, 2014, pp. 9 y ss. y "Los contratos de seguro y de mediación de seguros en la "propuesta de Código Mercantil", Revista de derecho mercantil, núm. 292, 2014, pp. 23 y ss. 
seguro $^{5}$ y ha sido abordado igualmente en el proyecto de armonización del derecho contractual europeo ${ }^{6}$.

\section{MODIFICACIONES EN EL RÉGIMEN DEL SEGURO DE RESPONSABILIDAD CIVIL}

Entre las numerosas cuestiones que habría que abordar en la elaboración de un nuevo texto legal que regulase el contrato de seguro, necesariamente algunas de ellas, de gran interés e importancia, tienen como objeto el régimen del seguro de responsabilidad civil comenzando por la correcta delimitación del riesgo asegurado que subyace especialmente en esta categoría. Algunas de las materias a las que pretendemos referirnos no proceden, sin embargo, del texto original de 1980, sino que fueron introducidas con reformas posteriores e, incluso, alguna otra ha sido eliminada de la Ley y llevada la cuestión a otro texto diferente.

Las posibles modificaciones que proponemos no resultan nada pacíficas y plantean además especiales dificultades para cerrarse, de modo que no hay un criterio uniforme en torno a cómo deben ser abordadas. Parece cierto, sin embargo, que suscitan interesantes debates propiciados por la enorme repercusión que esta categoría de seguros tiene en una sociedad cada vez más exigente -en lo que a la gestión de sus riesgos se refiere- y también globalizada, en la que ha de tenerse en cuenta la práctica de otros países, en particular, en la Unión Europea.

La demanda de este tipo de productos ha crecido de una forma notable y sostenida por la iniciativa de los particulares, pero en otras ocasiones es el mandato del legislador el que establece su exigencia proliferando los seguros cuya contratación es obligatoria. Por estos motivos, apenas esbozados, el seguro de responsabilidad civil ha ido generando problemas diversos sobre las que se han pronunciado los tribunales a lo largo del tiempo, también, por supuesto el Tribunal Supremo, lo que se pone especialmente de manifiesto en la generosa Jurisprudencia que se ha generado en los últimos años ${ }^{7}$.

En concreto, tres son las cuestiones que se pretenden tratar:

1. Las cláusulas de delimitación temporal del riesgo, o más exactamente de la cobertura y su (re)consideración como cláusulas limitativas (art. 73.2 LCS).

\footnotetext{
5 Vid., entre otros, Bataller Grau, J. "Principios de Derecho europeo del contrato de seguro (PEICL): un paso importante hacia la integración de los mercados nacionales de seguros en la Unión Europea", Revista española de seguros, núm.132, 2007, pp. 497 y ss, y Los principios de Derecho europeo del contrato de seguro, editorial Pontificia Universidad Javeriana, Bogotá, Colombia, 2012, passim.

${ }^{6}$ Quintans EirÁs, M ${ }^{\mathrm{a}} \mathrm{R}$. "El contrato de seguro en el proyecto de armonización del derecho contractual europeo", Revista de derecho mercantil, núm. 290, 2013, pp. 293 y ss. Los principios están llamados a integrarse en un futuro corpus de Derecho contractual europeo, vid., p. 299.

7 Blázquez Martín, R. "Actualizaciones y novedades de la jurisprudencia del tribunal supremo sobre el contrato de seguro", Diario La Ley, núm. 9466, 29 de julio de 2019, pp.1 y ss. y "Pronunciamientos de la Sala Primera del Tribunal Supremo sobre seguros obligatorios", Diario La Ley, núm. 9546, 3 de enero de 2020, pp. 1 y ss.
} 
2. La acción directa del perjudicado contra el asegurador y su carácter inmune frente a las excepciones que puedan corresponder al asegurador contra el asegurado (art. 76 LCS).

3. El regreso de una mención a los seguros obligatorios a la ley reguladora del contrato de seguro (art. 75 LCS, derogado).

\section{CLÁUSULAS DE DELIMITACIÓN TEMPORAL DEL RIESGO}

La importancia del tiempo y su delimitación en el contrato de seguro constituyen algunos de los aspectos centrales que han de tenerse en cuenta para su correcto funcionamiento que viene marcado por estas circunstancias temporales ${ }^{8} \mathrm{y}$, tratándose de seguros de responsabilidad civil, estos factores se presentan aún más decisivos, debiendo ser considerados con mayor cuidado y precisión.

Por estas circunstancias, las cláusulas de delimitación temporal del riesgo, o de la cobertura que se presta durante un tiempo determinado, y su consideración como cláusulas limitativas de los derechos de los asegurados, constituyen uno de los temas que más han suscitado la atención por la controversia que plantea tanto a la doctrina como al quehacer de los tribunales. Ante esta conflictividad, ha he tenerse en cuenta además que la consideración del siniestro como el surgimiento de una deuda de responsabilidad civil, que puede tratarse de un hecho que se forma sucesivamente, puede plantear importantes problemas a la hora de ser delimitado?

Seguramente, uno de los temas más problemáticos, por no decir el que más entre todos ellos, presente en el régimen del seguro de responsabilidad en la Ley 50/1980 es el párrafo segundo del art. 73, incorporado tras la modificación que tuvo lugar del texto por la disposición adicional sexta de la Ley 30/1995, de 8 de noviembre de ordenación y supervisión de los seguros privados ${ }^{10}$. Ciertamente, este carácter conflictivo proviene en parte de la escasa claridad con que fue redactado este apartado, junto a los importantes efectos excluyentes que las situaciones establecidas en esta norma determinan para la cobertura a dispensar. Los plazos establecidos por este apartado no pueden calificarse precisamente como generosos, permitiendo trasladar en numerosas ocasiones al asegurado el problema de afrontar la deuda de responsabilidad civil ${ }^{11}$,

\footnotetext{
8 Vid., por todos, Veiga Copo, A.B., La dimensión temporal del contrato de seguro, Cívitas, Madrid, 2011, pp. 16 y ss, "[T]odo, absolutamente todo en el contrato de seguro viene marcado por la dimensión temporal".

9 Tapia Hermida, A.J., Guía del contrato de seguro, Thomson Reuters Aranzadi, Cizur Menor, 2018, p. 123.

10 Vid., SÁnchez CALERo, F. "La delimitación temporal del riesgo en el seguro de responsabilidad civil tras la modificación del artículo 73 de la ley de contrato de seguro", Estudios de Derecho Mercantil. Homenaje al profesor Justino Duque Domínguez, II, Universidad de Valladolid, Valladolid, 1998, pp. 131 y ss.

11 Como señala Veiga Copo, A. B. La dimensión temporal ... cit., p. 139, estas cláusulas fueron una creación de las entidades aseguradoras a modo de reacción desmesurada frente a la avalancha de reclamaciones por daños en este tipo de seguros y que supusieron una auténtica revolución a la hora de definir y limitar temporalmente la cobertura del riesgo asegurado.
} 
incluso en supuestos en los que durante largo tiempo ha tenido suscrito un seguro de estas características ${ }^{12}$.

Su inclusión estuvo pensada para atender aquellos supuestos en los que no hay coincidencia entre el hecho causante de los daños y perjuicios (el momento de la ocurrencia del hecho desencadenante de la responsabilidad civil, ocurrente basis) y la reclamación efectuada por el/los perjudicado/s (el momento en el que el asegurado/ tercer perjudicado reclama al asegurador dicha prestación, claims made) y solo uno de estos acontecimientos tiene lugar durante el periodo de vigencia de la póliza, bien con anterioridad a la celebración del contrato, en este caso, el hecho causante, bien una vez finalizada la relación contractual, en este supuesto, la reclamación.

\section{Reconsideración como cláusulas limitativas}

Se presentan, en consecuencia, dos tipos de cláusulas de delimitación temporal de la cobertura, por un lado, las que tienen una naturaleza retroactiva o retrospectiva y, por otro, las de naturaleza subsiguiente o prospectiva, siendo tratadas ambas como cláusulas limitativas de los derechos de los asegurados por indicación expresa del art. 73.2 de la Ley, debiéndose en consecuencia ser destacadas especialmente en el texto y aceptadas expresamente por escrito por los asegurados tal y como en este caso indica el art. 3 del texto legal.

Ante esta doble consideración establecida por la propia norma, y la confusión tanto a nivel conceptual como de tratamiento que genera al no distinguir entre cláusulas delimitadoras y cláusulas limitativas, parece claro que se trataría esta de una de las modificaciones que debe ser abordada en un nuevo texto regulador del contrato de seguro para clarificar ante qué tipo de cláusula nos encontramos ${ }^{13}$ y zanjar la discusión sobre esta distinción que se ha convertido en un problema clásico de la interpretación de los contratos de seguro, particularmente, a nivel jurisprudencial ${ }^{14}$.

\footnotetext{
${ }^{12}$ Han de tenerse en cuenta además los llamados long tail risks, riesgos que causan siniestros tardíos o de aparición diferida con consecuencias, en ocasiones, de gran alcance y que provocan graves perjuicios. Entre las modalidades contractuales que suelen dan cobertura a este tipo de riesgos se encuentran los seguros de responsabilidad por productos, las responsabilidades civiles profesionales, D\&O, etc., que resultan especialmente problemáticos en la práctica al tiempo que imprescindibles para la cobertura de este tipo de riesgos. Vid., Hill Prados, Ma C. "Las cláusulas “claims made”. ¿¿¿Fin de la polémica???”, Estudios sobre el futuro Código Mercantil. Libro Homenaje al profesor Rafael Illescas Ortíz, Universidad Carlos III, Madrid, 2015, p. 1404.

13 “Estamos ante cláusulas delimitadoras del riesgo en su ámbito temporal, o acaso ante limitativas de derechos cuando no puntualmente lesivas?” Es la pregunta que se formula VeIGA Copo, A. B. "La temporalidad en el contrato de seguro. Riesgo y siniestro: una ecuación interesadamente compleja”, Revista Ibero Latinoamericana de Seguros, Bogotá (Colombia), enero-junio de 2010, pp. 14 y 16. Por su parte, Pertínez Vílchez, F. "Tutela de los consumidores y cláusulas abusivas en el contrato de seguro", en AA.VV., Retos y desafios del contrato de seguro: del necesario aggiornamento a la metamorfosis del contrato, A.B. Veiga Copo (dir), Civitas Thomson Reuters, Madrid, 2020, pp. 600 a 603 considera esta distinción como perniciosa.

14 Destaca Veiga Copo. A.B. La dimensión temporal..., cit., p. 140, cómo fue la STS de 20 de marzo de 1991 la primera que aplicó a estas cláusulas la calificación de limitativas de los derechos de los asegurados, vinculándolas a la necesidad de tener que cumplir con los requisitos establecidos en el art. 3 de la LCS y
} 
Seguramente esta reforma deba ir acompañada de una modificación del contenido del art. 3 para proporcionar una solución más amplia y definitiva, pensando siempre en la protección del asegurado, pero que se presenta igualmente compleja si se quiere mantener el carácter certero y preciso de la Ley actual. En todo caso, se ha de situar esta materia en la línea de la disciplina general al respecto sobre condiciones generales de la contratación, donde no se contempla la figura de las cláusulas limitativas.

También resultarían necesarias, para una correcta delimitación de este tema, reformas en el propio concepto de seguro de responsabilidad civil que tradicionalmente se ha

generando como tan bien explica el profesor VeIGA la confusión entre lo meramente formal, la delimitación y selección de los riesgos cubiertos con lo que realmente es una limitación en sentido estricto que sólo procede cuando previamente existe y está correctamente delimitado el derecho. En este caso, lo que hay que delimitar es el alcance del riesgo asumido que la entidad aseguradora pretende asumir. Vid., igualmente, Verdera y Tuells, E. "La cláusula Claims Made ante la jurisprudencia del TS: Una primera revisión crítica", Estudios sobre el aseguramiento de la responsabilidad en la gran empresa, F., Sánchez Calero, Madrid 1994, pp. 95 y ss.

Es cierto que la citada STS, tal y como puede consultarse en SÁnchez Calero, F. "La delimitación temporal de riesgo...", cit., pp. 1324 y ss, ante un supuesto en el que había de aplicarse una cláusula que delimitaba el riesgo asumido por la entidad aseguradora a través de una triple exigencia de que la producción del hecho dañoso, la denuncia del siniestro y la reclamación del tercero debían producirse dentro del periodo de vigencia del contrato, consideró ilícita esta cláusula en concreto por ser lesiva además de limitativa de los derechos de los asegurados. Esta resolución generó un fuerte rechazo por parte del sector asegurador, motivando la reforma que dio lugar al segundo apartado del art. 73 de la Ley 50/1980, y dominando su redacción al afirmar su carácter de limitativas de los derechos de los asegurados. Con ello, se superaban los obstáculos para poder ser consideradas cláusulas válidas, dejando a un lado su consideración como lesivas.

Sentencias posteriores como la STS 961/2000 de 16 de octubre, o la STS 853/2006 de 11 septiembre, por señalar sólo algunas, han establecido una correcta doctrina de separación entre ambas categorías de cláusulas considerando que la cláusula limitativa opera para restringir, condicionar o modificar el derecho del asegurado a la indemnización una vez que el riesgo objeto del seguro se ha producido, mientras que la cláusula delimitadora de riesgo es la que especifica sobre qué clase de ellos se ha constituido en objeto del contrato. En concreto señala que son estipulaciones delimitadoras del riesgo aquellas que tienen por finalidad delimitar el objeto del contrato: a) qué riesgos constituyen dicho objeto; b) en qué cuantía; c) durante qué plazo y d) en que ámbito temporal. Por tanto, las cláusulas delimitadoras del riesgo son aquellas mediante las cuales se concreta el objeto del contrato fijando los riesgos que en caso de producirse hacen surgir en el asegurado el derecho a la prestación y en la entidad aseguradora el deber de atenderla. Esta diferenciación se ha perpetuado a lo largo del tiempo, de modo que resoluciones mucho más recientes como las STS 58/2019, de 20 de enero o la 609/2019, de 14 de noviembre siguen basándose en ella. Vid., sobre la primera de estas sentencias, vid., LACASA GARCía, R., "Cláusulas limitativas y cláusulas delimitadoras del riesgo, responsabilidad asegurable y mora del asegurador en el seguro de responsabilidad civil. Comentario de la Sentencia del Tribunal Supremo [1. $\left.{ }^{a}\right]$ de 29 de enero de 2019", Revista de Derecho Mercantil, núm. 313, 2019, pp. 1-20 (versión digital). Igualmente, con carácter general, Miranda Serrano, L. Ma, "Control de transparencia de las condiciones del contrato de seguro (más allá de los clásicos requisitos de inclusión)", AA.VV. Un Derecho del seguro más social y transparente, J. Bataller Grau, $\mathrm{M}^{\mathrm{a}} \mathrm{J}$. Peñas Moyano (dirs), Cívitas Thomson Reuters, Madrid, 2017, pp. 72 y ss.

Por su parte, el dictamen del Consejo de Estado 2145/1994, de 22 de diciembre, en relación a la modificación prevista de la Ley 50/1980, consideró una medida acertada la modificación de su art.73 para admitir la validez de este tipo de cláusulas que la práctica consideraba necesarias, pero añadía que la redacción propuesta, que finalmente se mantuvo a pesar de estas observaciones, resultaba equívoca, siguiendo el camino abierto por numerosas decisiones jurisprudenciales, al considerar abusivas determinadas cláusulas limitativas de los derechos del asegurado, cuando se trata, más bien, de "un problema de determinación precisa del riesgo asegurado". Vid., Hill Prados, Ma C., op. cit., p. 1411. 
considerado amplio en exceso ${ }^{15}$, incorporando alguna precisión relativa al tiempo de la cobertura.

En este sentido, parece que hay consenso acerca de la consideración de que las cláusulas que contribuyen a delimitar el riesgo objeto de cobertura, tanto por lo que se refiere a su aspecto objetivo, territorial, espacial o temporal, forman parte del objeto principal del contrato de seguro y regulan la prestación principal del asegurador, ${ }^{16}$ de modo que como tales cláusulas no requerirían de ningún otro requisito para ser consideradas válidas y aplicables plenamente. De este modo, la delimitación temporal del riesgo en sí y dentro de los márgenes establecidos por la Ley con el objetivo de su individualización, no provoca una limitación de derechos, sino que delimita el riesgo asumido en el contrato y el ámbito de la cobertura en el tiempo del asegurador.

Pero como se señala, en la norma están recogidas además como cláusulas limitativas per se, y, como tales, necesitarían para su eficacia cumplir los requisitos del art. 3 . $\mathrm{Su}$ carácter limitativo derivaría, en consecuencia, del efecto que producen sobre el contenido natural del contrato y por ello en un seguro con una cláusula de delimitación temporal, el siniestro no es solo el hecho causante de la responsabilidad civil -como resultaría de la definición que de este tipo de seguro hace el art. 73.1- sino también de la reclamación del perjudicado durante la vigencia de la póliza.

En otros ámbitos y como consecuencia de que no existe ni se ha planteado una intervención legal al respecto, las cláusulas que delimitan el riesgo no se consideran limitativas de los derechos de los asegurados. Así la reciente sentencia del Tribunal Supremo, de 6 de julio, núm. 397/2020, ha señalado que las cláusulas que determinan las coberturas personales en un seguro de accidentes, atendiendo a si se trata de un tripulante o de ocupante del vehículo -aeronave, en este caso-, tienen la consideración de cláusulas delimitadoras del riesgo, aunque se trata de una delimitación material y no puramente temporal, y no de cláusulas limitativas de los derechos de los asegurados.

Para complicar esta cuestión, la Jurisprudencia de nuestro alto Tribunal ha creado la categoría de cláusulas sorprendentes o sorpresivas como eslabón en la línea que separa-o, más bien, que une- a las cláusulas delimitadoras del riesgo de las cláusulas limitativas ${ }^{17}$. En concreto, el Tribunal Supremo hace una interpretación novedosa

\footnotetext{
15 SAnz Parrilla, M., op. cit., p. 817.

16 Pertínez Víllchez, F., op. cit., p. 592. El considerando 19 de la Directiva 93/13 establece que: "las cláusulas que definen o delimitan claramente el riesgo asegurado y el compromiso del asegurador no son objeto de una apreciación del carácter abusivo, ya que dichas limitaciones se tienen en cuenta en el cálculo de la prima abonada por el consumidor".

La STJUE de 23 de abril de 2015, asunto C-96/14, Van Hove vs CNP Assurance SA) hace referencia a las exigencias de claridad y comprensión de las cláusulas modo que "no sólo resulte inteligible para el consumidor en el plano gramatical, sino también que el contrato exponga de manera transparente tanto el funcionamiento concreto del mecanismo al que se refiere la cláusula como la relación entre dicho mecanismo y el que establezcan otras cláusulas, de manera que el consumidor de que se trate esté en condiciones de valorar, basándose en criterios precisos e inteligibles, las consecuencias económicas que se deriven para él..."

17 Así, TAPia Hermida, A.J., en su blog jurídico, vid., http://ajtapia.com/2020/09/las-sorpresas-que-danlas-clausulas-sorprendentes-en-los-contratos-de-seguro-y-sus-consecuencias-a-proposito-de-la-sentenciadel-pleno-de-la-sala-primera-de-lo-civil-del-tribunal-supremo-421-2020-de/
} 
de las condiciones de los contratos de seguro que se presenta como una suerte de mutación genética de las condiciones delimitadoras del riesgo cubierto en tránsito hacia las cláusulas limitativas de los derechos de los asegurados pudiendo calificarse de lesivas cuando la sorpresa puede calificarse de abusiva.

Consideramos, sin embargo, que las cláusulas de delimitación temporal del riesgo a las que se refiere el contenido de este art. 73.2 de la Ley no deben ser tratadas como tales -ni sorpresivas ni sorprendentes-, ni deben seguir siendo calificadas como cláusulas limitativas por la norma que las contemple. Por el contrario, ambos tipos de cláusulas deben ser reconducidas a sus estrictos términos para evitar el mantenimiento de situaciones que tanta confusión generan. Por ello, tal vez lo más oportuno en una hipotética nueva redacción sea prescindir de toda referencia al tipo de cláusula de que se trate, a semejanza de lo planteado en la redacción del Anteproyecto de Ley de Código Mercantil ${ }^{18}$ y que otros intentos de reforma anteriores también solicitaban. Con ello se evitarían los importantes desajustes que se ponen de manifiesto entre la práctica de este seguro y las exigencias todavía contempladas por el art. 73.2 de la Ley.

\section{Ampliación del tiempo de cobertura}

Del Anteproyecto de Ley de Código Mercantil, en concreto, del proyecto art. 58244 nos agrada, por un lado, la referencia temporal acogida en el propio concepto de seguro de responsabilidad civil, que menciona la cobertura por cualquier hecho previsto en el contrato y producido durante su vigencia. También la ampliación del tiempo de cobertura en las cláusulas de esta naturaleza, tanto las de cobertura retroactiva como las de naturaleza subsiguiente a dos años como mínimo una vez finalizado el contrato. El plazo mínimo de cobertura de un año se considera realmente breve $^{19}$. Incluso sería recomendable un ámbito temporal más amplio a estos dos años situando así al Derecho español en la línea de otros Derechos comparados, fijando un plazo general para todos los seguros de responsabilidad más generoso aun cuando existan tipos de seguros concretos para los que se establezca un plazo más amplio.

\section{Validez de las cláusulas de delimitación temporal del riesgo unidimensionales}

Consideramos igualmente que en una nueva redacción de los preceptos dedicados a esta materia y siguiendo la Jurisprudencia contemplada por la STS núm. 252/2018, de 26 de $a_{b r i 1^{20}}$, que plantea un debate que no había tenido lugar hasta el momento, sería

\footnotetext{
En concreto, se refiere a este tema y a las llamadas cláusulas sorpresivas o sorprendentes como; "[E]l viaje de la delimitación a la lesividad, pasando por la limitación".

18 Vid., Hill Prados, Ma C., op. cit., p. 1403. Si bien es cierto, como señala la autora, que se elimina la calificación de limitativas, pero no se definen tampoco como delimitadoras.

19 VÉRgez SÁnchez, M., AA VV. "Reflexiones sobre algunos aspectos relevantes de la reforma de la ley de contrato de seguro", Liber amicorum, profesor José María Gondra, Madrid, Barcelona, Buenos Aires, Sao Paulo, 2012, pp. 307 y 308.

20 Vid., al respecto, TAPia Hermida, A. J. Guía..., cit., p. 125 a 127. Igualmente, LóPez y García DE LA Serrana, J. Cuestiones controvertidas en materia de Derecho de seguros, Dykinson, Madrid, 2020, pp.
} 
oportuno incorporar una referencia a la validez de las cláusulas unidimensionales. El objetivo sería reforzar la admisibilidad de ambos tipos de cláusulas por separado cumpliendo con los requisitos de validez establecidos. Esta doctrina ha sido reiterada en las sentencias núm. 170/2019, de 20 de marzo y núm. 185/2019, de 26 de marzo.

Para evitar todo tipo de confusión al respecto debe considerarse innecesaria la acumulación de las coberturas retroactiva y subsiguiente en un mismo contrato de seguro, de modo que no se haga depender la validez de una de ellas de la presencia en el contrato de la otra. Se trata de dos cláusulas independientes que poseen cada una de ellas sus propios requisitos, tal y como puede desprenderse de la dicción literal del art. 73.2, -dos incisos separados por un punto y seguido, comenzando el segundo inciso con el adverbio asimismo-. En consecuencia, como se ha señalado, su redacción resulta manifiestamente mejorable, también en relación a esta cuestión particular, para evitar interpretaciones contradictorias al respecto.

Matizar esa consideración se considera pertinente de tal modo que se trataría de elegir la póliza que mejor se ajuste a cada una de las situaciones concretas en las que se encuentre el asegurado.

\section{LA ACCIÓN DIRECTA DEL TERCER PERJUDICADO}

Otra de las cuestiones que consideramos requiere ser modificada es la regulación de la acción directa del perjudicado contra el asegurador, sin entrar a considerar, en absoluto, su reconocimiento a favor del perjudicado, o de sus herederos, para poder actuar directamente contra el asegurador y exigirle que cumpla la prestación del seguro. No se cuestiona tampoco su consideración como un derecho propio del perjudicado que no tiene su origen en el contrato de seguro sino en la propia norma, sin perjuicio de que quede a él vinculado y ser necesaria su existencia ofreciendo una determinada cobertura, y que es diferente de la que corresponde al asegurado. Se superó de esta manera la separación de las dos relaciones jurídicas existentes, asegurador y asegurado; asegurado y tercer perjudicado, al permitir el vínculo del perjudicado con el asegurador para poder exigirle el cumplimiento de la obligación de indemnizar el daño causado por el asegurado.

La generalización que se produjo con ocasión de la entrada en vigor de la Ley 50/1980 de la existencia de ese derecho propio del tercer perjudicado frente al asegurador a todo contrato de seguro de responsabilidad civil, se erigió en uno de los elementos fundamentales de esta categoría de contratos adquiriendo esa función social de gran importancia que le sigue correspondiendo y que tiene como finalidad proteger a los

166 a 173. En concreto, en la citada sentencia se plantea un conflicto en torno a si una cláusula subsiguiente tiene condicionada su validez a la existencia de una cláusula de naturaleza retroactiva, concluyendo su validez por no ser acumulables los requisitos exigidos por la norma de la cláusula subsiguientes respecto de la de carácter retrospectivo. 
perjudicados por hechos dañosos ${ }^{21}$ reforzando el traslado de las consecuencias del daño producido del patrimonio del asegurado al patrimonio del asegurador.

Sin embargo, a pesar de la enorme importancia práctica que supuso la generalización de la acción directa con el contenido del art. 76 Ley de contrato de seguro, su redacción fue calificada casi inmediatamente después por la doctrina como confusa y poco afortunada ${ }^{22}$, debido en parte al contenido que se añade respecto al reconocimiento de esta acción directa y que provocó que resultara dificultoso entender a qué se estaba refiriendo concretamente el legislador que se limita a admitir el ejercicio general de la acción, pero no determina en qué consiste ni su naturaleza ni su concreto contenido.

Además, ha de tenerse en cuenta que esta acción directa a pesar de la fuerza que conlleva, al menos la que aparentemente se deduce del texto, necesariamente se va a ver condicionada por los límites establecidos en la delimitación del riesgo, límites objetivos, temporales y cuantitativos ${ }^{23}$, en tanto que el derecho del perjudicado contra el asegurador está limitado a la suma asegurada de manera que la aseguradora no puede quedar obligada más allá de la propia obligación del asegurado, lo que convierte al alcance de esta acción directa y los límites de su ejercicio en una cuestión realmente controvertida.

\section{Reconsideración del carácter inmune de la acción directa}

En particular, se considera que es necesaria una reflexión sobre el mantenimiento de su carácter inmune en la Ley, en relación a las excepciones que puedan corresponder al asegurador contra el asegurado y que no podrían ser oponibles frente al tercer perjudicado, así como las que se podrían oponer directamente a este. ${ }^{24}$ La cuestión de la inmunidad ${ }^{25}$ es una fuente de conflictos y tensa extraordinariamente las relaciones

\footnotetext{
21 Sánchez Calero, F., La Ley de Contrato de Seguro. Comentarios a la Ley 50/1980, de 8 de octubre, y a sus modificaciones, F. Sánchez Calero (dir), Aranzadi, Navarra, 1999, p. 1119.

22 Vid., SÁnchez Calero, F., La Ley de Contrato..., cit., p. 1209 y n. 2.

23 VeIga Copo, A.B., La acción directa del tercer perjudicado en los seguros de responsabilidad civil, Madrid, Cívitas, 2013, p. 37.

24 Siguiendo al maestro Sánchez CAlero, F., La Ley de Contrato..., cit., p. 1237, reproducimos aquí las posibles situaciones a tener en cuenta para que se puedan tener lugar las excepciones a plantear por el asegurador frente al asegurado en relación al art. 76 de la LCS. A estos efectos, interesa distinguir: "a) Por un lado, los hechos de los que depende el nacimiento de la obligación del asegurador, que son fundamentalmente, en primer término, la existencia de un contrato válido, con unos límites determinados de cobertura (o si se quiere con un determinado contenido) y, en segundo lugar, la verificación del evento dañoso previsto en el contrato, esto es, que se haya producido un hecho del que surge una responsabilidad civil. Estos hechos, en cuanto son constitutivos del derecho del asegurado (y correlativamente de la obligación del asegurador) han de probarse, en principio por el propio asegurado, y no podemos calificar su falta de excepciones en sentido estricto. b) Por otro lado, aparecen los hechos impeditivos o extintivos del derecho del asegurado, que significan la liberación del asegurador de acuerdo con la relación jurídica interna que deriva del contrato de seguro y que dependen normalmente de la conducta del asegurado (pago de la prima, incumplimiento de los deberes sobre declaración del riesgo, denuncia de la existencia del siniestro, etc). Estos hechos, cuya prueba corresponde al asegurador, constituyen verdaderas excepciones a la pretensión del asegurado, que serán oponibles o no al perjudicado conforme a la normativa del artículo 76".

25 Esta inmunidad, como señala VeIGA Copo, A. B. La acción directa..., cit., p. 209, fortalece la acción directa, pero no debe ni considerarse de modo absoluto ni tampoco ser confundida con la indemnidad pues
} 
entre las partes implicadas lo que queda reflejado en las resoluciones de los tribunales. Resulta claro, por tanto, que la redacción del art. 76 no ha ofrecido pautas claras que hayan aportado seguridad para la resolución de los conflictos que se han ido suscitando ante el orden judicial ${ }^{26}$.

La utilización de esta expresión puede causar además confusión en el propio perjudicado, haciéndole caer en la creencia de que nada puede oponer la compañía aseguradora para evitar hacer frente al pago de la indemnización que le puede corresponder ${ }^{27}$, cuando lo cierto es que el derecho del perjudicado frente al asegurador va a estar condicionado por los límites que este haya pactado con el asegurado y, en particular, la correcta delimitación del riesgo o riesgos que se aseguran en el contrato en particular. Por ello, siendo cierto que el objetivo de la Ley ha sido proteger al perjudicado reduciendo las excepciones que pueda oponer el asegurador, en ningún caso, las que podría oponer al propio asegurado, por tanto, estrechando los márgenes de su actuación para eludir el pago de la correspondiente reparación, es cierto también que esta protección mejoraría sensiblemente si se precisasen cuáles pueden ser tales excepciones y en mayor medida las que sean inoponibles frente al tercero perjudicado.

Las excepciones propias o en sentido estricto como aquellas que puede oponer la aseguradora al tercero porque están basadas en los vínculos que relacionan al asegurado que causa el daño con el tercero o las basadas en la culpa exclusiva del perjudicado delimitan el ámbito de ejercicio de la acción directa ${ }^{28}$. Pero resulta cierto que tal inmunidad no va a impedir que el asegurador pueda oponer excepciones de carácter

no son sinónimos, sino que la cualidad de indemne implica libre o exento de daño, que no es el supuesto al que se refiere el legislador.

26 Veiga Copo, A. B. La acción directa..., cit., en especial, pp. 249 y ss.

27 En un conflicto derivado de un accidente que se produjo mientras el actor se encontraba en las instalaciones de la empresa esperando a que su hermano terminase su jornada laboral, se desprendió una viga metálica que cayó sobre su pie, provocándole múltiples daños que acabaron con la amputación parcial del mismo. Se reclama la cantidad de $100.723,74$ euros por las lesiones, la incapacidad y los gastos médicos. Antes de la celebración del juicio el perjudicado llegó a un acuerdo con el asegurado que alcanzó la cifra de 100.000 euros por daños, secuelas y por los días de hospitalización, más otros 12.922 euros por gastos médicos, renunciando a cualquier acción que pudiera corresponderle. A pesar de ello, se interpuso demanda contra la compañía aseguradora en ejercicio de la acción directa conforme al art. 76 de la LCS. El juzgado de primera instancia desestimó la demanda. Sin embargo, la SAP 3/2013, de Guipúzcoa, de 11 de enero, estimó el recurso de apelación interpuesto. En síntesis, alegó que no existe cosa juzgada ni vulneración de la doctrina de los actos propios, pues el acuerdo transaccional fue entre el perjudicado y la empresa asegurada, y la renuncia a las acciones lo fue frente a dicha empresa, quedando incólume el derecho a reclamar a la aseguradora. Recordó que, ante el ejercicio de la acción directa, el art. 76 de la LCS establece el principio de invulnerabilidad o inmunidad de la acción del perjudicado a las excepciones personales que pudiera tener el asegurador contra el asegurado. Tras examinar los daños y las secuelas, terminó concediendo al actor la cantidad de 63.648,58 euros. Veremos en el siguiente apartado como la STS $87 / 2015$, de 4 de marzo considera que no es posible el ejercicio de la acción directa como consecuencia del previo pago realizado por el asegurado.

28 En este caso, señala Veiga Copo, A. B. La acción directa..., cit., p. 254, que "[P]ropiamente, no estamos ante una excepción, sino ante un hecho impeditivo de la propia responsabilidad del asegurado y por ende, lógicamente, del asegurador. Si quién causa exclusiva y debido a su propia culpa el daño, y no ha participado en el iter siniestral, por tanto en el hecho ilícito el asegurado, no hace ninguna responsabilidad. A pesar de la calificación, confusa y manifiestamente errónea del legislador e art. 76, no estamos ante una excepción que se base en la relación entre el asegurado y tercero, no hay tal". 
impropio frente a esta acción directa. Entre ellas las referidas a hechos relacionados con el contenido del contrato de seguro suscrito entre la compañía de seguros y el tomador, que producen daños en un tercero y quedan excluidos en la póliza o no se aseguran con las características con las que se produjo, como la inexistencia de un contrato de seguro que sea válido en el momento de la reclamación, bien por ser declarado nulo o porque ya se ha extinguido previamente, o incluso porque la relación del asegurado lo es con otro asegurador distinto. En definitiva, hechos impeditivos de la cobertura que también podrían ser opuestos por la entidad aseguradora frente al asegurado ${ }^{29}$ y que una interpretación literal del art. 76 podría dar a entender que el perjudicado sería inmune a ellas y, sin embargo, son también hechos constitutivos de su derecho de reparación, precisamente para no tenga lugar.

A estas ya mencionadas, deben añadirse otras situaciones posibles que impedirían el ejercicio de la acción directa como la inexistencia del derecho al resarcimiento por los daños causados por el asegurado porque no están presentes los presupuestos para el nacimiento de la responsabilidad o incluso porque la misma no es imputable al asegurado. Podría darse también el caso de que quien debería tener la legitimación activa para realizar la reclamación correspondiente carezca de ella.

En definitiva, se resultaría muy conveniente determinar de una forma más precisa cuáles son aquellas situaciones en las que el asegurador podrá oponer frente al perjudicado o perjudicados las excepciones que correspondan en el caso de que las haya, para delimitar de la forma más precisa posible la efectividad real de la pretensión que el tercero puede ejercer, de modo que tenga éxito en su interposición.

\footnotetext{
29 Vid., al respecto, las SSTS 40/2009, de 23 de abril y 484/2018 de 11 septiembre. Igualmente, la STS 200/2015, de 17 de abril, aclara que tampoco pueden oponerse aquellas cláusulas de exclusión de riesgos que tengan su fundamento en la especial gravedad de la conducta dañosa del asegurado. Por tanto, la aseguradora puede oponer al perjudicado que el daño sufrido es porque ha tenido lugar un riesgo que está excluido en el contrato.

A su vez, la STS 730/2018, de 20 de diciembre recuerda que la delimitación del riesgo resulta oponible no solo al tomador y/o asegurado, sino también al tercero perjudicado que ejercita la acción directa "no como una excepción en sentido propio, sino como consecuencia de la ausencia de un hecho constitutivo del derecho de aquel sujeto frente al asegurador. Ese derecho podrá haber nacido frente al asegurado en cuanto causante del daño, pero el asegurador no será responsable, porque su cobertura respecto al asegurado contra el nacimiento de la obligación de indemnizar sólo se extiende a los hechos previstos en el contrato. En consecuencia, queda excluida la acción directa, pues el perjudicado no puede alegar un derecho al margen del propio contrato". Especialmente interesante resulta también el conflicto resuelto por la STS 321/2019, de 5 de junio, en la que se pone de manifiesto cómo las limitaciones al ejercicio de la acción directa por parte del perjudicado también pueden provenir de la situación concreta de las partes en conflicto, en concreto, que la asegurada sea la administración pública sanitaria, entrando en juego la jurisdicción contencioso-administrativa como la única competente para condenar a la administración. El demandante, aunque solo demande a la aseguradora, no podrá limitarse a invocar que la administración asegurada le ha causado un daño y a probar que dicho daño está cubierto en la póliza, sino que debe acreditar y obtener un pronunciamiento de que la Administración ha incurrido en responsabilidad patrimonial. Concluye entonces la citada resolución que sería contrario a la legalidad utilizar la acción directa en vía civil para reclamar a la aseguradora una indemnización superior a la fijada por la jurisdicción contencioso administrativa, porque ello equivaldría a impugnar el acto administrativo. Vid., BlázQuEz MARTín, R. "Actualizaciones y novedades...", cit., pp. 12 y 13.
} 
En este sentido ha de tenerse en cuenta que el asegurado está obligado a manifestar al perjudicado o sus herederos la existencia del contrato, así como su contenido, para que puedan conocer cómo ha sido delimitado el riesgo cubierto, en particular, las exclusiones contempladas expresamente en el contrato, a los efectos del ejercicio de esta acción directa. Otra posibilidad que se podría contemplar en un hipotético nuevo texto son las situaciones en las que el tercer perjudicado va a poder proceder al ejercicio de la acción directa contra el asegurador, a semejanza de lo previsto por el art. 15:101 de los Principios de Derecho europeo del contrato de seguro ${ }^{30}$.

El art. 76 de la Ley de contrato de seguro solo establece que el asegurador podrá oponer la culpa exclusiva del perjudicado, así como las excepciones personales que tenga contra él, lo que resulta totalmente insuficiente, también para tratar de configurar esta acción directa como una acción autónoma de la responsabilidad civil asegurada, en definitiva, como un mecanismo indemnizatorio abstracto de los terceros perjudicados o de sus herederos, en su caso $^{31}$, por lo que ha precisado la correspondiente interpretación doctrinal y las importantísimas aportaciones realizadas por la jurisprudencia.

Ante las dificultades de llevar a cabo posibles enumeraciones de supuestos ${ }^{32}$, una posible reducción, mejor aún, una más correcta delimitación de la inmunidad puede quedar equilibrada con la posibilidad de que el tercer perjudicado o sus herederos puedan en el mismo proceso en el que se ejerce la acción directa contra el asegurador dirigirla también simultáneamente contra el responsable del daño, situación que en la práctica se acepta sin problema con el fundamento de la solidaridad entre ambos que es la base de esta acción directa y que se refuerza en el caso de que la suma asegurada sea inferior al daño efectivamente causado, puesto que en ningún supuesto un asegurador puede estar obligado frente a un tercero que lo que debe como límite de esa suma. Aquella previsión, en todo caso, fue ya contemplada expresamente por el Anteproyecto de Ley de Código Mercantil en su art. 582-47.2, como una facilidad procesal para alcanzar los objetivos propuestos ${ }^{33}$.

\footnotetext{
30 Artículo 15:101 Reclamación directa y excepciones

(1) La víctima tendrá derecho de reclamación directa contra el asegurador en la medida en que tomador del seguro o el asegurado, según sea el caso, sea responsable, siempre y cuando:

(a) El contrato de seguro sea obligatorio, o

(b) El tomador del seguro o el asegurado sea insolvente, o

(c) El tomador del seguro o el asegurado se encuentre en liquidación, o

(d) La víctima haya sufrido un daño personal, o

(e) La ley que rija la responsabilidad contemple la acción directa.

31 Tapia Hermida, A. J. "El proceso de reforma del régimen del seguro de responsabilidad civil...", cit., p. 151. El objetivo, señala TAPIA, sería trasladar a la norma que sólo cuando existe responsabilidad civil del asegurado puede exigirse la actuación de la entidad aseguradora; en otras palabras, ante la inexistencia de responsabilidad de asegurado, la entidad queda liberada. Vid., igualmente, "El seguro de responsabilidad civil en la Propuesta de Código Mercantil”, Revista de la Asociación Española...cit., p.22.

32 Vid., Sánchez Calero, F. La Ley de Contrato..., cit., pp. 1253 y 1254.

33 Tapia Hermida, A. J. "El seguro de responsabilidad civil en la Propuesta de Código Mercantil”, Revista de la Asociación Española...cit., pp. 23 y ss.
} 


\section{Relaciones entre la entidad aseguradora, el asegurado y el tercer perjudicado}

Resultaría también muy interesante determinar en alguna medida las situaciones que vinculan al asegurador con el asegurado, dejando a un lado la consideración de una conducta dolosa por su parte, en principio no oponible al perjudicado ni aunque la póliza contemplase esta exclusión y sin perjuicio del derecho a repetir contra el asegurado, así como las situaciones posibles que pueden vincular al asegurado con el tercer perjudicado y que pueden suponer un reconocimiento, una aminoración o incluso la falta éxito en el ejercicio de la acción directa por parte del perjudicado y dar origen a una posible excepción personal, que podría posteriormente ser opuesta por el asegurador. Entre tales situaciones se encontraría la extinción del derecho a percibir la indemnización de la entidad aseguradora como consecuencia del pago, total o parcial, ya realizado por el asegurado con carácter extrajudicial o la prescripción de los derechos del tercero. Asimismo, también habría que tener en cuenta una posible compensación o remisión de la deuda o situaciones más determinantes como una posible situación de necesidad que haya originado la conducta del asegurado e incluso una actuación legítima en defensa propia.

Este es el supuesto planteado por la STS 87/2015, de 4 de marzo, recurso núm. $839 / 2013^{34}$ en la que se incide en la consideración de la obligación entre el asegurador y asegurado como una obligación solidaria de tal modo que al procederse a la extinción del crédito por uno de los posibles deudores, el otro, en este caso la compañía aseguradora, puede alegar el pago como excepción personal frente a la reclamación que el tercer perjudicado pueda realizar, teniendo en cuenta además que dejó de serlo puesto que había recibido la cuantía pactada en relación al siniestro producido. En definitiva, el asegurador puede oponer al perjudicado las excepciones personales que tenga con éste, y, entre ellas, se encuentran las basadas en la relación entre el tercero perjudicado y el asegurado.

Otra circunstancia que debería tenerse en cuenta es que no puede ser igual el funcionamiento de la acción directa en aquellos casos en los que nos encontremos ante seguros voluntarios o, en su caso, ante seguros obligatorios, si bien es cierto que el cometido del art. 76 fue precisamente ampliar este derecho del perjudicado a todas las modalidades de seguro de responsabilidad civil, separándolo de la obligatoriedad del seguro donde había sido introducida esta acción en primer lugar ${ }^{35}$ y poniendo claramente de manifiesto que la acción directa no es patrimonio exclusivo de los seguros obligatorios de responsabilidad civil ${ }^{36}$.

Una referencia a esta diferenciación se encontraba en la Propuesta de Código Mercantil de 2013, pero se eliminó en su paso al Anteproyecto de Ley de Código Mercantil. En concreto su art. 592-47 comenzaba indicando que "sin perjuicio de lo previsto en el régimen de los contratos de seguro a los que se refiere el artículo precedente", por

\footnotetext{
34 López y García de la Serrana, J., op. cit., pp. 152 a 156.

35 Sánchez Calero, F. La Ley de contrato..., cit., pp. 1209 y 1210 y 1213 y ss.

36 Veiga Copo, A. B. La acción directa..., cit., p. 218.
} 
tanto, haciendo expresa salvedad de lo que puedan disponer respecto al ejercicio de la acción directa en los regímenes expresos de seguros obligatorios.

En esta categoría de seguros para que la aseguradora esté obligada a pagar por un siniestro producido antes de que se haya satisfecho la primera prima por el tomador es necesario que así se haya pactado o que medie culpa o falta de diligencia de la aseguradora en su condición de acreedora, bien porque no pasó al cobro el recibo, o lo pasó en cuenta equivocada, o por cualquier otra circunstancia de la que se deduzca que no se produjo el impago por culpa del tomador.

Por tanto, si bien es cierto que la falta de pago de la primera prima es una excepción oponible al tercer perjudicado con carácter general, salvo pacto en contrario ${ }^{37}$, sin que surja la obligación de cobertura para la entidad aseguradora en el supuesto de que se produzca el siniestro, no lo es en algunos seguros obligatorios como el del automóvil si el siniestro tiene lugar antes de que la entidad aseguradora haya comunicado la resolución del contrato al tomador del seguro, tal y como plantea la STS 267/2015, de 10 de septiembre, recurso núm. 544/2013 $3^{38}$. De ahí, tal vez, la conveniencia, como se verá en el apartado siguiente, de recuperar una referencia a los seguros de responsabilidad civil obligatorios en el régimen contractual.

\section{PREVISIÓN DE LOS SEGUROS OBLIGATORIOS DE RESPONSABILIDAD CIVIL}

El tercer tema que queremos traer aquí es el relativo a recuperar una previsión en el régimen del contrato de seguro acerca de la obligatoriedad de determinados seguros de responsabilidad civil, como condición imprescindible para la realización de determinadas actividades que pueden ser consideradas como potencialmente peligrosas, bien en sí mismas consideradas, o bien atendiendo a su carácter reiterativo. ${ }^{39}$ Ello obedece al interés general por proteger a las potenciales víctimas frente a las posibles consecuencias perjudiciales de la realización de estas actividades a través de

\footnotetext{
37 Sanz Parrilla, M. op. cit., p. 833. Vid., al respecto, la STS 682/2019, de 17 de diciembre, en recurso núm. 3264/2016 Comentada por SALAS CARCELLER, A. "Tercero perjudicado en el seguro de responsabilidad civil”, Revista Aranzadi Doctrinal, núm. 7, julio, 2020, pp. 1-5. Resulta muy oportuna la pregunta que se realiza el autor de este comentario al plantearse, “¿qué sentido tiene que haya de prevalecer a favor del tercero un seguro -que podría no existir- cuando el tomador de dicho seguro no ha dado cumplimiento a las obligaciones propias del contrato?"

38 Señala el fundamento tercero de la citada sentencia, en su apartado 3, que "la falta de pago de la primera prima antes de la ocurrencia del siniestro no produce el efecto "ope legis" de liberar al asegurador de su obligación de indemnizar, como señala el recurrente en su escrito. No basta para resolver el contrato del seguro obligatorio por impago de la primera prima demostrar la culpa del tomador, sino que, como señala el precepto reglamentario transcrito (art. 20.2), frente a terceros, es necesario acreditar, además, la comunicación recepticia dirigida al tomador del seguro declarando resuelto y sin efecto alguno el contrato, lo que se adecua a las exigencias normativas para que pueda producir el efecto de quedar liberada la aseguradora de su obligación de indemnizar. Hasta tanto no se acredite haber efectuado tal comunicación, frente a terceros, el impago de la primera prima o prima única es inoponible frente a quien ejercita la acción directa del art. 76 LCS, por subrogación, como es el supuesto contemplado en el presente caso".

39 Tapia Hermida, A. J. Guía... cit., p. 136.
} 
la existencia de estos seguros, con independencia de otras posibles sanciones que el ordenamiento jurídico pueda establecer.

\section{Disposición adicional segunda de la Ley 20/2105, de 14 de julio}

El art.75 de la 50/1980 fue derogado con ocasión de la entrada en vigor de la Ley 20/2015, de 14 de julio, de ordenación, supervisión y solvencia de las entidades aseguradoras y reaseguradoras. A partir de entonces la previsión de la obligatoriedad de determinados seguros se sitúa en la disposición adicional segunda de esta norma de naturaleza administrativa, con un contenido mucho más amplio que el previamente contemplado por la norma reguladora del contrato.

Llama la atención, sin embargo, que previamente el Anteproyecto de Ley de Código Mercantil incluyera el seguro obligatorio en su art. 582-46 ${ }^{40}$, seguramente sin tener en cuenta que se proyectaba una nueva Ley de ordenación del sector asegurador. Aunque pudiera parecer que estamos ante un precepto semejante al art. 75 de la Ley 50/1980 derogado $^{41}$, el Anteproyecto de Ley de Código Mercantil incluye precisiones que resultan de gran importancia tales como que la norma que regule estos seguros ha de tener rango de Ley ${ }^{42}$, la necesidad de fijar los límites de la suma asegurada como una de las cuestiones fundamentales a tener en cuenta ${ }^{43}$, así como la aplicación prioritaria de la norma específica que regule la figura en el caso de que se haya previsto.

La disposición adicional segunda de la Ley reguladora de la actividad de las entidades aseguradoras tiene, sin embargo, un contenido significativamente más amplio atendiendo a la naturaleza de la norma en la que se integra ${ }^{44}$, aunque parte del mismo

\footnotetext{
40 Vid., al respecto, PAVELEK, E. "El seguro obligatorio: aspectos colaterales". En: AA.VV. Retos y desafios del contrato de seguro...", cit., pp. 279 y 280.

${ }^{41}$ Sobre el contenido de este precepto, vid., igualmente, PAVELEK, op. cit., pp. 261 y 263, en relación a las tres disposiciones que contemplaba y que fueron eliminadas de la LCS, en concreto, el establecimiento de la obligatoriedad del seguro para aquellas actividades que se determinasen por el gobierno. Esta primera cuestión quedó desdibujada con la transferencia de las competencias del Estado a las diferentes Comunidades Autónomas. En segundo lugar, la no autorización por parte de la administración de aquellas actividades sin que previamente se acreditase por el interesado la existencia del contrato de seguro, lo que impedirá obtener la licencia correspondiente para su ejercicio constatándose en ocasiones la paradoja de encontrarse ante seguros obligatorios sin regulación de su contenido. Por último, la imposición de la correspondiente sanción administrativa en caso de falta de seguro, cuestión que excede el ámbito puramente contractual y que nada tiene que ver con su disciplina convencional.

42 Sobre el rechazo de la previsión de la necesidad de una ley para el establecimiento de un seguro obligatorio en el proceso de aprobación de la Ley 50/1980, tanto en la comisión del Congreso como después en el Senado, dando lugar a la normativa que ha estado vigente hasta la entrada en vigor de la Ley 20/2015, el 1 de enero de 2016, según la cual sería el Gobierno determinase la obligatoriedad de un seguro de responsabilidad civil para el ejercicio de ciertas actividades, de modo que se podía realizar a través de una norma reglamentaria, vid., SÁnchez CALERo, F. La Ley de Contrato..., cit., pp. 1192, 1193 y 2013 y ss.

43 Tapia Hermida, A. J. "El seguro de responsabilidad civil en la Propuesta de Código Mercantil”, Revista de la Asociación Española...cit., p. 22.

${ }^{44}$ La última parte de su apartado 2 contempla cuestiones puramente administrativas: "La realización de actividades careciendo del correspondiente seguro obligatorio será constitutivo de infracción administrativa muy grave, salvo lo dispuesto en su normativa específica. Será sujeto infractor la persona física o jurídica
} 
tiene trascendencia contractual, coincidiendo en parte con el proyectado en el Código ya mencionado. En particular, han de tenerse en cuenta las siguientes consideraciones: se podrá exigir a quienes ejerzan determinadas actividades que presenten un riesgo directo y concreto para la salud o para la seguridad de las personas, incluida la seguridad financiera, la suscripción de un seguro u otra garantía equivalente que cubra los daños y perjuicios que puedan provocar y de los que sean responsables. Se matiza además que la garantía exigida deberá ser proporcionada a la naturaleza y alcance del riesgo cubierto. Por tanto, se recoge una habilitación general para la exigencia de seguro que cubra la realización de determinadas actividades por una cuantía que además debe ser proporcionada, en el sentido de adecuada, equilibrada, en definitiva, atendiendo a los riesgos que se cubren, su carácter y posible extensión.

En esta disposición también se recoge la obligación de que suscripción de seguros debe establecerse mediante normas con rango de Ley y además que deberán contar con un informe preceptivo de la Dirección General de Seguros y Fondos de Pensiones, o del órgano competente de las Comunidades Autónomas, con el objeto de que puedan formular observaciones en materia de técnica aseguradora ${ }^{45}$.

La primera de las exigencias ha sido considerada siempre totalmente razonable si se tiene en cuenta que la expansión del seguro obligatorio ha tenido lugar a través de disposiciones de todo rango normativo y competencial. Sin embargo, también es cierto que delimitar su regulación a este rango formal de la norma tal vez no solucione la problemática de la enorme proliferación de seguros de responsabilidad civil exigidos obligatoriamente por los poderes públicos, pues ha de tenerse en cuenta que la gran mayoría de normas tanto estatales como autonómicas que incorporan esta exigencia ya tienen rango de ley ${ }^{46}$.

Respecto al segundo requerimiento de la norma resulta igualmente oportuno, si bien en la práctica son las compañías aseguradoras quienes tienen que ofrecer el producto asumiendo las correspondientes coberturas y lógicamente si ello no es posible, escaso cumplimiento va a poder darse al mandato del legislador. Por ello, y dado que no existe una correspondencia entre la obligación que se impone a los ejercientes de una determinada actividad con la obligación de las entidades aseguradoras de poner a su disposición un seguro, la previsión de solicitar igualmente un informe a las entidades tal vez no resulte una idea descabellada con la intención de comprobar si es factible

que viniera obligada a la suscripción del seguro, pudiendo ser sancionado con multa de 1.000 a 20.000 euros. La instrucción y resolución del procedimiento sancionador corresponderá a la Administración pública competente por razón en la materia cuya regulación impone la suscripción del seguro obligatorio". 45 Se contempla, igualmente, otra disposición de naturaleza administrativa según la cual la Dirección General de Seguros y Fondos de Pensiones comunicará a la Comisión Europea, de acuerdo con el registro que se desarrolle reglamentariamente y que gestionará el Consorcio de Compensación de Seguros, los seguros obligatorios existentes en España, indicando las disposiciones específicas que regulan el seguro obligatorio. Para cumplir con este mandato los órganos competentes de las Comunidades Autónomas debían comunicar a la Dirección General de Seguros, en el plazo de tres meses desde la entrada en vigor de esta Ley, los seguros obligatorios existentes en su respectiva comunidad, y en el plazo de un mes desde su aprobación, los seguros obligatorios que se establezcan con posterioridad, indicando las especificaciones del apartado anterior.

46 PaveleK, E., op. cit., p. 262. 
asumir la oferta y afrontar la demanda de este tipo de seguros, cuando una ley concreta disponga su obligatoriedad.

Ha de señalarse, igualmente, que la norma que en la Ley 20/2015 hace referencia a la póliza del contrato de seguro, el art. 95, no distingue en absoluto entre seguros voluntarios y seguros obligatorios, a diferencia de textos anteriores, de modo que cualquiera que sea la situación, las condiciones contractuales y modelos de pólizas no estarán sujetas a autorización administrativa ni deberán ser objeto de remisión sistemática a la Dirección General de Seguros y Fondos de Pensiones, quedando toda la documentación a su disposición. El art. 117 del Real Decreto 1060/2015, de 20 de noviembre, tampoco hace ninguna alusión al respecto ${ }^{47}$.

Sí contempla este Real Decreto en su disposición adicional primera, ${ }^{48}$ conforme a lo que indica el apartado 3 de la disposición adicional segunda de la Ley 20/2015, las referencias mínimas relativas al registro de seguros obligatorios que necesariamente debía crearse en cumplimiento de lo dispuesto por el art. 179.4 de la Directiva Solvencia II, Directiva 2009/38/CE, de 25 de noviembre.

Este registro ha sido desarrollado por la Resolución de 18 de diciembre de 2015 de la Dirección General de Seguros y Fondos de Pensiones y su gestión encomendada al Consorcio de compensación de seguros ${ }^{49}$ continuando en la actualidad en fase de desarrollo.

\section{Reconsideración de su presencia en la ley reguladora del contrato de seguro}

Lo que se plantea en este caso es la conveniencia de recuperar para el régimen contractual una previsión de este tipo que acompañe a la disposición adicional

\footnotetext{
${ }^{47}$ Disposición adicional primera. Registro de seguros obligatorios. 1. El Registro de seguros obligatorios, al que se refiere el apartado 3 de la disposición adicional segunda de la Ley 20/2015 de 14 de julio, contendrá toda la información actualizada relativa a los seguros obligatorios. El contenido de la información y las especificaciones sobre el procedimiento de remisión se establecerán mediante resolución de la Dirección General de Seguros y Fondos de Pensiones. 2. El acceso a los datos del Registro de seguros obligatorios será público, a través de la web del Consorcio de Compensación de Seguros. 3. La gestión del Registro corresponde al Consorcio de Compensación de Seguros. Todas las operaciones que requieran esta gestión se realizarán por medios electrónicos. 4. El Consorcio de Compensación de Seguros elaborará anualmente, sobre la base de los datos disponibles a 31 de diciembre, un informe del contenido del registro, que será puesto a disposición de la Dirección General de Seguros y Fondos de Pensiones y, a través de ésta, a los órganos de las Comunidades Autónomas competentes en la materia.

48 Disposición adicional primera. Registro de seguros obligatorios. 1. El Registro de seguros obligatorios, al que se refiere el apartado 3 de la disposición adicional segunda de la Ley 20/2015 de 14 de julio, contendrá toda la información actualizada relativa a los seguros obligatorios. El contenido de la información y las especificaciones sobre el procedimiento de remisión se establecerán mediante resolución de la Dirección General de Seguros y Fondos de Pensiones. 2. El acceso a los datos del Registro de seguros obligatorios será público, a través de la web del Consorcio de Compensación de Seguros. 3. La gestión del Registro corresponde al Consorcio de Compensación de Seguros. Todas las operaciones que requieran esta gestión se realizarán por medios electrónicos. 4. El Consorcio de Compensación de Seguros elaborará anualmente, sobre la base de los datos disponibles a 31 de diciembre, un informe del contenido del registro, que será puesto a disposición de la Dirección General de Seguros y Fondos de Pensiones y, a través de ésta, a los órganos de las Comunidades Autónomas competentes en la materia.

49 https://www.consorseguros.es/web/registro-seguros-obligatorios
} 
segunda de la Ley 20/2015, de 14 de julio, o, como se ha señalado -en tanto que su previsión en la Ley del contrato de seguro no ha tenido ninguna trascendencia ni, por lo tanto, generado problemática- ${ }^{50}$, mantener su eliminación, teniendo en cuenta además que las Comunidades Autónomas tienen transferida la competencia sobre esta materia y que han proliferado los textos legales estableciendo seguros de este tipo, a veces por la mera intención de dotar de contenido a las competencias transferidas. Ha de matizarse, además, que en muchas ocasiones ni siquiera se distingue entre la obligación de celebrar un determinado contrato de seguro y el seguro obligatorio en sí.

Tal vez esta sea la cuestión que resulta necesario ordenar: la concreción de cuándo un seguro debe calificarse de este modo y qué requisitos mínimos se requieren para que pueda ser considerado como tal, entre ellos que la cobertura pueda ser asumida por una entidad aseguradora y que sea exigido por un texto de carácter general en el que quede reflejado, por supuesto, al menos mínimamente, cuál deba ser su contenido para que su exigencia no pierda sentido, como puede suceder en el caso de una vana generalización.

No se trata, por tanto, de agravar el régimen de la responsabilidad exigible, sino más bien de evitar que existan dudas en cuanto a su exigencia, en particular, que esta no pueda quedar al arbitrio de la administración correspondiente ni, por supuesto, a la oferta del mercado. ${ }^{51}$ Más bien, al contrario, se deben existir unas bases lo suficientemente claras para propiciar un acceso y un tratamiento equilibrado de los seguros que se califiquen como obligatorios, proceso en el que debe intervenir activamente la propia administración.

El requerimiento del seguro en sí, sin embargo, en algunas ocasiones será más bien una obligación de asegurarse para determinados colectivos, teniendo en cuenta además que esta situación no es propia únicamente de los seguros de responsabilidad civil, sino de del seguro en general. En todo caso, el que pretenda ejercer determinadas actividades está sometido a un deber legal de celebrar un contrato de seguro que nace de la norma que impone este comportamiento a determinados sujetos y que además ha de verificarse antes del comienzo de la actividad y mantenerse a lo largo de su ejercicio.

En realidad, y con el objetivo de centrar el debate, solo nos referimos a esta única diferenciación entre seguros voluntarios y obligatorios de responsabilidad civil y a la necesidad de que se atienda su diversidad, pero después del tiempo transcurrido desde la entrada en vigor de la Ley 50/1980 tal vez también habría que plantearse tener en

\footnotetext{
50 PaveleK, E., op. cit., p. 262. Opina el autor que si este artículo nunca se hubiera incorporado a la LCS no hubiera pasado absolutamente nada. Vid., p. 263.

51 Resultan en este sentido muy ilustradoras las aportaciones de Eduardo PAVELEK, op. cit., pp. 264 y 273, al destacar que el procedimiento más seguido para exigir la contratación de un seguro obligatorio es la utilización de una cláusula estandarizada en la que no se refleja ninguna precisa en relación al contenido de la cobertura y en la que además se suele incluir que aparecerá en el correspondiente desarrollo reglamentario que queda pospuesto, lógicamente: "Las empresas que... puedan comportar riesgo, deberán disponer de un seguro de responsabilidad civil que cubra los daños de los que deban responder, en la cuantía que reglamentariamente se determine". Como contrapunto a esta ausencia de precisión debe añadirse, sin embargo, la frecuencia con la que suele recogerse en los contratos como riesgo excluido "las responsabilidades que sean objeto de cobertura por un seguro obligatorio".
} 
cuenta otras posibles distinciones en relación a esta categoría de seguros atendiendo bien al tipo de responsabilidad que se asegura, bien a la persona asegurada.

Esta apreciación conducente a la diferenciación de supuestos posibles de cobertura, podría extenderse a otro tipo de cuestiones relacionadas con la forma de manifestarse los daños, bien continuados o en serie, por tanto, cuando por una misma causa se originan daños a personas diferentes y en momentos también diferentes, y haciendo referencia también a los daños diferidos que solo se manifiestan cuando transcurre un determinado plazo de tiempo, pero sin que se haya producido la prescripción del derecho de crédito del perjudicado.

En ambos casos, y ante las posibles maniobras de las entidades aseguradoras para evitar su cobertura, una correcta protección del asegurado reclama su previsión en la norma correspondiente precisamente para asegurar la actuación de la entidad cuando se den las premisas para ello: existencia de varios siniestros y fijación de un periodo de tiempo razonable para que puedan plantearse las reclamaciones correspondientes que, como se ha tenido oportunidad de señalar constituye una de las cuestiones más problemáticas y conflictivas de los seguros de responsabilidad civil y que requiere de revisión.

\section{BIBLIOGRAFÍA}

AA.VV. Insurtech y nuevas tendencias de la responsabilidad civil, J. Jimeno Muñoz (coord.), Sepin, Madrid, 2109.

AA.VV. Retos y desafios del contrato de seguro: del necesario aggiornamento a la metamorfosis del contrato, A.B. Veiga Copo (dir), Civitas Thomson Reuters, Madrid, 2020.

Bataller Grau, J. "Principios de Derecho europeo del contrato de seguro (PEICL): un paso importante hacia la integración de los mercados nacionales de seguros en la Unión Europea", Revista española de seguros, núm.132, 2007, pp. 497-498.

- "La reforma de la Ley de Contrato de Seguro", Revista de Derecho Mercantil, núm. 279, 2011, pp. 203-233.

BlázQUez Martín, R. "Actualizaciones y novedades de la jurisprudencia del tribunal supremo sobre el contrato de seguro", Diario La Ley, núm. 9466, 29 de julio de 2019, pp.1-16.

- "Pronunciamientos de la Sala Primera del Tribunal Supremo sobre seguros obligatorios", Diario La Ley, núm. 9546, 3 de enero de 2020, pp. 1-15.

Hill Prados, M ${ }^{a}$ C. "Las cláusulas “claims made”. ¿¿¿Fin de la polémica???”, Estudios sobre el futuro Código Mercantil. Libro Homenaje al profesor Rafael Illescas Ortiz, Universidad Carlos III, Madrid, 2015, pp. 1403-1420.

ACASA GARCíA, R. “Cláusulas limitativas y cláusulas delimitadoras del riesgo, responsabilidad asegurable y mora del asegurador en el seguro de responsabilidad civil. Comentario de la Sentencia del Tribunal Supremo [1."] de 29 de enero de 2019", Revista de Derecho Mercantil, núm. 313, 2019, pp. 1-20 (versión digital).

López y García de la Serrana, J. Cuestiones controvertidas en materia de Derecho de seguros, Dykinson, Madrid, 2020. 
Miranda Serrano, L. Ma " "Control de transparencia de las condiciones del contrato de seguro (más allá de los clásicos requisitos de inclusión)”, AA.VV., Un Derecho del seguro más social y transparente, J. Bataller Grau, Ma J. Peñas Moyano (dirs), Cívitas Thomson Reuters, Madrid, 2017, pp. 45-108.

Pavelek, E. "El seguro obligatorio: aspectos colaterales", en AA.VV., Retos y desafios del contrato de seguro: del necesario aggiornamento a la metamorfosis del contrato, A.B. Veiga Copo (dir), Civitas Thomson Reuters, Madrid, 2020, pp. 259-286.

Pertínez Vílcchez, F. “Tutela de los consumidores y cláusulas abusivas en el contrato de seguro". En: AA.VV. Retos y desafios del contrato de seguro: del necesario aggiornamento a la metamorfosis del contrato, A.B. Veiga Copo (dir), Civitas Thomson Reuters, Madrid, 2020, pp. 589-611.

Quintáns EIRÁs, M $M^{\mathrm{a}} \mathrm{R}$. "El contrato de seguro en el proyecto de armonización del derecho contractual europeo", Revista de derecho mercantil, núm. 290, 2013, pp. 293-326.

Salas Carceller, A. "Tercero perjudicado en el seguro de responsabilidad civil", Revista Aranzadi Doctrinal, núm. 7, julio, 2020, pp. 1-5.

Sánchez Calero, F., La Ley de Contrato de Seguro. Comentarios a la Ley 50/1980, de 8 de octubre, y a sus modificaciones, F. Sánchez Calero (dir), Aranzadi, Navarra, 1999

- "La delimitación temporal del riesgo en el seguro de responsabilidad civil tras la modificación del artículo 73 de la ley de contrato de seguro", Estudios de Derecho Mercantil. Homenaje al profesor Justino Duque Domínguez, II, Universidad de Valladolid, Valladolid, 1998, pp. 1315-1330.

SAnz Parrilla, M. "Sección 6a. Seguro de responsabilidad civil. Introducción y artículos 68 a 70”, Revista Española de Seguros, núms. 143-144, 2010, pp. 815-836.

TAPIA Hermida, A. J. "El proceso de reforma del régimen del seguro de responsabilidad civil: desde la vigente Ley de Contrato de Seguro hasta el Anteproyecto de Ley de Código Mercantil. La delimitación objetiva de la cobertura ante la nueva regulación de las condiciones generales y las cláusulas limitativas", Revista española de seguros, núm.158, 2014, pp. 143-160.

- "El seguro de responsabilidad civil en la Propuesta de Código Mercantil", Revista de la Asociación Española de Abogados Especializados en Responsabilidad Civil y Seguro, núm. 49, 2014, pp. 9-24.

- "Los contratos de seguro y de mediación de seguros en la "propuesta de Código Mercantil", Revista de derecho mercantil, núm. 292, 2014, pp. 23-50.

- Guía del contrato de seguro, Thomson Reuters Aranzadi, Cizur Menor, 2018.

- Veiga Copo, A. B. "La temporalidad en el contrato de seguro. Riesgo y siniestro: una ecuación interesadamente compleja", Revista Ibero Latinoamericana de Seguros, Bogotá (Colombia), enero-junio de 2010, 1-46.

- La dimensión temporal del contrato de seguro, Cívitas, Madrid, 2011.

- Los principios de Derecho europeo del contrato de seguro, editorial Pontificia Universidad Javeriana, Bogotá, Colombia, 2012. 
- La acción directa del tercer perjudicado en los seguros de responsabilidad civil, Madrid, Cívitas, 2013.

Verdera Y Tuells, E. "La cláusula Claims Made ante la jurisprudencia del TS: Una primera revisión crítica”, Estudios sobre el aseguramiento de la responsabilidad en la gran empresa, F., Sánchez Calero, Madrid 1994, pp. 75-134.

VÉrgez SÁNCHEZ, M., AA VV. "Reflexiones sobre algunos aspectos relevantes de la reforma de la ley de contrato de seguro", Liber amicorum, profesor José María Gondra, Madrid, Barcelona, Buenos Aires, Sao Paulo, 2012, pp. 293-310. 